\section{The hygiene-sanitary control in the wild game meats}

\author{
Germana Giuggioli, ${ }^{1}$ Alberto Olivastri, ${ }^{2}$ \\ Luca Pennisi, ${ }^{3}$ Domenico Paludi, ${ }^{3}$ \\ Adriana Ianieri, ${ }^{4}$ Alberto Vergara ${ }^{3}$ \\ ${ }^{1}$ Freelance Hygienist Veterinarian, \\ Rome; ${ }^{2}$ ASUR Marche Area Vasta 5 \\ Ascoli Piceno/San Benedetto del Tronto; \\ ${ }^{3}$ Faculty of Veterinary Medicine, \\ University of Teramo; ${ }^{4}$ Department of \\ Food Science, University of Parma, \\ Parma, Italy
}

\begin{abstract}
The use of game meat as a food source is currently a growing trend in our country. These products have strong and historic ties with cultural and culinary tradition, but are also appreciated for their sensory and nutritional characteristics. A major contributor to the supply of this type of product is hunting. Practiced since the dawn of time for survival, hunting has evolved into a recreational activity with substantial commercial interests. Of particular importance in this context is hunting of large ungulates. The progressive urbanization of the population has allowed for the re-establishment of bush and wooded areas that represent the ideal habitat of species such as the wild boar, whose numbers are increasing throughout the country. It is therefore clear that implementation of safety rules regarding the hunting and consumption of game meat needs to be urgently addressed. The understanding and application of rules isn't always easy since the health law is intertwined with that of hunting, and the decision- making power left to the different regions does not contribute to a uniform application throughout the country. The aim of this study was to examine the norms that regulate the use of large wild game meat intended for human consumption and their applicability in hunting activities. From the comparison of the data reported in the literature and our field experience the rules implementation and the problems are evaluated. Operational procedures are then proposed to simplify some of the most difficult aspects and fill in the gaps highlighted.
\end{abstract}

\section{Introduction}

The law N. 157 of 11/02/1992 its subsequent amendments rule on wildlife and hunting. Article 1 Subparagraph 1 states that wildlife is a heritage to be safeguarded in the interests of the national and interna- tional community. Article 1 Subparagraph 3 states that, in addition, regions shall adopt rules relating to the management and the protection of all wildlife species. In accordance with this law, international conventions and directives must indicate the methods, procedures and technical figures of the hunting of boars in the territories. This is to manage, monitor and survey the wildlife. The technical figures included in Article 2, subparagraph 1 of the same law) apply to wildlife technicians with a technical-scientific degree, hunters licensed for collective hunting and conductors of hunting dogs. These are prescribed by the province, through special examinations, prior attendance of specific courses organized and carried out in the hunting territory in question [ambito territoriale di caccia (ATC)]. The regional council determines paths, educational activities and requirements for access to the courses, the modalities of the examination and the exam committee composition. The qualifications are valid throughout the region and the province will issue permits.

\section{Materials and Methods}

Hunting of wild animals in accordance with current legislation Regulation EC $\mathrm{n}$. $852 / 2004$, is a primary production and the hunter is a primary producer. Therefore the legally and physically responsible person is the hunter, who becomes responsible for the traceability of his product in accordance with EC Regulation N.178/2002. In EC Regulation 853/2004, Section 4, Chapter 1, points 1 to 5 it is established that: people who hunt wild game in order to market it for human consumption must have sufficient knowledge about diseases of game to correctly identify these at the scene of the hunt. It is sufficient for one person among the group of hunters to have sufficient knowledge of normal anatomical, physiological and behavioural framework of wild game, odd behaviour and pathological changes due to diseases, environmental contamination or factors which may affect human's health after consumption; hygiene and proper handling techniques and laws concerning the conditions of animal and public health for the marketing of wild game. The trained person applies a label to each piece and attaches a statement per carcass with a serial number, stating there aren't anomalies. This declaration must state the date, the time and the place of the slaughter. The viscera may not accompany the body except for swine, in which case the head and diaphragm must be inspected for Trichinella. In the case of anomalies being identified, the trained person who carriesout
Correspondence: Germana Giuggioli, Via Luigi De Marchi 154, 00143 Roma (RM), Italy.

E-mail: giuggioli.germana@gmail.com

Key words: Wild boar; Hunt; Legislation; Hygiene; Food safety.

Contributions: the authors contributed equally.

Conflict of interest: the authors declare no potential conflict of interest.

Received for publication: 5 July 2017. Revision received: 25 September 2017. Accepted for publication: 26 September 2017.

This work is licensed under a Creative Commons Attribution-NonCommercial 4.0 International License (CC BY-NC 4.0).

CCopyright G. Giuggioli et al., 2017 Licensee PAGEPress, Italy

Italian Journal of Food Safety 2017; 6:6875

doi:10.4081/ijfs.2017.6875

the examination must inform the competent authority. In this case all the bowels except for stomach and intestines must accompany the body. The method of transportation must be such that sanitary regulations are strictly adhered to, ensure that the carcasses are not crowded, that every carcass is accompanied by an identification number for tracking and traceability and that the refrigeration is at a maximum temperature of $7^{\circ}$. According to EC Regulation N. $853 / 2004$, Subparagraph 3, Section 4, Chapter 2, the products of hunting can be used for: 1) own consumption; 2) direct sale to the final consumer or retailer; 3) local consumption, where local consumption is limited at 1 big game animal, or 500 small game animals per hunter in a year; 4) marketing.

A comparison between the current legislation and the official controls made by the veterinaries of the ASUR Marche, area Vasta 5, Ascoli Piceno-San Benedetto on meat inspected during the hunting seasons showed the following. The hunter will adhere to the relevant legislation for the protection of wildlife law N. 157 year 1992, regional law, hunting calendars and provisions referring to meat of domestic or wild swine to check for Trichinella in meat (Regulation EC 1375/2015). In this case Regulation EC 854/2004 Article 1 Point 3/A, doesn't apply to primary production for private domestic use. The hunter has the responsibility to present only the pluck (heart, tongue, lungs, diaphragm and liver) to the veterinary service of local health for Trichinella examination Regulation EC 
$1375 / 2015$ and the post- mortem inspection (Regulation EC 854/2004). The meat cannot be eaten until notification of the successful outcome of this exam has been issued.

A Trichinella exam is performed by withdrawing 10 grams of diaphragm tissue. The portion is sealed in a bag labelled with the same number of the clump plate made by the province in the hunting territory [ambito territoriale di caccia (ATC)] and is sent for analysis to a laboratory recognized by article 12, Regulation EC 882/2004, which can be part of a slaughterhouse or experimental zooprophylactic institute [Istituto Zooprofilattico Sperimentale (IZS)].

The current procedure has to show tracking and traceability. If the Trichinella exam result is positive (presence of the parasite) the meat must be destroyed. Alternatively, should the Trichinella exam certify the absence of the parasite, the veterinary service issues a certificate of suitability for consumption. EC Regulation $853 / 2004$, Article 1, Paragraph 3, Point E exempts the hunter who supplies small quantities of wild game directly to the final consumer or the local retailers. According to the application guidelines of Regulation EC 853/2004, small amount is defined as 1 big game animal or 500 small game animals per hunter per year. The term local is defined as in the province or the neighbouring province. It further always prohibits the sale to festivals and events (Law N. 157 year 1992, Article 21). It is forbidden to sell dead game, not coming from farms, to festivals and gastronomic events. The hunter is obliged to declare the presence or the absence of anomalies (as listed above) and to document the origin of the game with a specific module, and attach the declaration of Trichinella's absence in the meat of susceptible species (wild boars). The hunter is responsible for the food safety of his product and must ensure the hygiene in all phases of production (killing, handling and trading). The trader who buys from the hunter must maintain a record of origin of the products, in accordance with Regulation EC $178 / 2002$ with regard tracking and traceability. Larger volumes of wild game meat, in relation to the definition of small amount, can be marketed for human consumption only if previously sent to a processing centre. Marketing, can only occur after prior step in a processing centre, or sectioning centre, or in a slaughterhouse approved in accordance with Regulation EC No $853 / 2004$, to be subjected to sanitary inspection in the manner provided by Regulation EC No 854/2004 and, if approved, submitted in the market.
Once the game animals are butchered, they are stored in a processing centre, ensuring that the carcasses are not crowded, that every carcass is accompanied by the identification number for tracking and traceability, the refrigeration is at a maximum temperature of $7^{\circ} \mathrm{C}$ and is escorted by a Hunter's statement that states the date, the time and the abatement MOD2. In case of boar the entire carcass is delivered without any deprivation of the parties. On arrival at the Centre, it must be examined as soon as possible by an official veterinarian in accordance with Regulation EC No 854/2004. A sample of diaphragm muscle must be collected in order to detect Trichinella before allowing distribution. The health marking is affixed only after a favourable outcome of the Trichinoscopic examination or postmortem inspection.

\section{Results}

From the audit activities practiced daily in the official control during hunting seasons were confirmed conditions of game meat depend on many factors. Muscle tissue is considered as virtually sterile, we can understand the importance of accurate shooting. Exposing of surfaces such as skin, hair/fleece or feathers and intestinal content will harbour a number of microorganisms. The difference between amateur and professional hunters is that professionals shoot the animals in the head or neck to minimize the damage to carcass. This is preferable, because a bad shot may have many undesirable consequences such as the exposure of the tissue to Enterobacteriaceae thus causing meat spoilage (Atanassova et al., 2008).

Badly placed shots may cause carcass damage and any shot in the gut will cause rapid microbial contamination of the carcass. A shot to the heart is instantly fatal causing minimal damage to the meat, little microbial contamination, and minimal fleeing distance after the shot. Microbiological studies were performed on fresh game meat in Europe. Based on the results of these studies, it can be concluded that the product has a very good hygienic status when properly processed. The low aerobic plate count values in the investigation resulted from several factors. Animals were shot on a well- organized hunt, coupled with fairly rapid opening and evisceration of the animals (within 90 minutes of death). Rapid evisceration is crucial, because within a few hours intestinal bacteria will pass through the intestinal barrier and contaminate muscle tissue. Sampling was carried out immediately afterwards and the samples were immediately cooled to $0+2^{\circ} \mathrm{C}$ until being examined. Additionally, lack of skill and hygiene during butchering will influence microbial contamination of the carcasses (Gill 2007, Paulsen et al., 2012.) When fresh carcasses have a good microbiological quality, conditions and time of transfer are very important to achieve adequate cooling of the carcass to avoid microbiological contamination and spoilage, especially during the warm season. Microbiological quality of meat can be very good, but is also extremely variable according to the conditions in which animals are shot, dressed and carcasses are butchered.

\section{Discussion}

If we study the existing regulations and legislated procedures regarding the handling of hunted products, there are critical issues in some passages of the game meat chain. Our field experience during the hunting seasons (gained in conjunction with the competent authority in the territories in question) and the data in the literature on microbiological parameters of carcasses highlighted a number of critical points. No overview or control of the whole chain by the veterinarian, particularly in the case of direct consumption and carcass disposal. Here it is the hunter who vouches for the safety of the product. The hunter, (who according to the law is a trained person) generally doesn't have specific skills necessary for adequate food inspection and control. This knowledge can fully guarantee the hygienic- sanitary quality of the product that is sold or consumed.

The first solution we propose is a reorganization of health surveillance in the whole food chain, mainly from the perspective of prevention. Initially the focus will be on the education of the hunter, thus ensuring ground level awareness of health risks from zoonotic diseases and the proper method of slaughter and handling a wild animal. This will minimize the sanitary risk and encourage sound hunting and management practices. Implementation of proper training and information can be achieved by offering training courses organized in collaboration with Territorial scopes of hunting, the regional and local health authorities, the provincial police and the State Forestry Corps, thus equating the degree of health risk information and knowledge between hunters and wildlife control officers. Additionally, authorized collection centres can be made available at hunting lodges to assist hunters with processing and sample collection. These may be sited in areas equidistant from the territory of hunting and such centres could be filled with proper equipment for gutting and handling of car- 
casses. The butchering and other processes may then be performed using good hygiene practices and may be monitored and supervised by the competent authority, or a veterinarian. The constant presence of the veterinarian would ensure the implementation of proper procedures and, in case of any faults, the arrangement for non-conformity of carcasses or its parts, thereby ensuring food safety. Collection centres, additionally, may utilize specialized companies to dispose of the viscera and other waste products in a legal, appropriate manner, thus minimizing the proliferation and transmission of potential pathogens. An alternative solution may be to centralize the processing of carcasses derived from hunting in a processing centre regardless of their destination. The opening of slaughtering lines, especially dedicated and controlled by an official veterinarian, would ensure, at all levels of the food chain, quality sanitation and safety of the meats derived from hunting, allowing compliance with the relevant regulations.

\section{Conclusions}

Throughout the country there is a growing interest in the health status of consuming wildlife products. The products of hunting activities, traditionally linked to local forms of gastronomic culture, today are a desirable alternative to traditionally farmed meat. Although in some cases venatory products were subjected to medical tests that have revealed the presence of the causative agents of diseases transmissible to humans and pets, it is not of such a serious nature to cause alarm. The microbiological quality of the meat, derived from wildlife hunting, is highly dependent on operating procedures put in place by the hunters. Numerous problems were reported at this level due to unsuitable handling procedures of carcasses, during trading, evisceration and skinning. Additional source of contagion is also represented by incorrect disposal of waste products of animal origin. With this background, the weak link in the chain game meat are the cases of direct consumption which lack an overall control of the production chain by a competent authority.

The legislature doesn't elect an Institutional Figure that will be a guarantor for the safety of the meat, but defers the final product warranty to the hunter, who, regardless of his level of education and experience, is largely ill equipped to handle the responsibility of this task. To address these problems, an operational proposal might be the confluence of the entire carcass to a slaughterhouse or to a processing centre, regardless of the destination of the meat. The confluence in structures recognized or opening a line of dedicated slaughter represents a guarantee for the proper handling of carcasses and the inspection control could be carried out by the competent authority. In the slaughterhouses the staff is qualified and has the necessary expertise at each stage of slaughter. There is an official veterinarian who oversees the work of the staff and that ensures the maintenance of hygienic-sanitary safety. The adoption of appropriate control procedures and specific protocols for health even in cases of direct-consumption and disposal, as well as ensuring all trades of the safety of food products, would also be able to provide useful insights for health surveillance of wildlife animal population.

Safety of meat must not depend on the final use but should always be the same regardless of the end use.

\section{References}

Atanassova V, Apelt J, Reich F, Klein G, 2008. Microbiological quality of freshly shot game in Germany. Meat Sci 78:414-9.

European Commission, 2002. Regulation of the European Parliament and of the Council of 28 January 2002 laying down the general principles and requirements of food law, establishing the European Food Safety Authority and laying down procedures in matters of food safety 178/2002. In: Official Journal L 31/1, 1/02/2002

European Commission, 2004. Regulation of the European Parliament and of the Council of 29 April 2004 on the hygiene of foodstuffs, 852/2004/CE. In: official journal L 139/1, 30/4/2004.

European Commission, 2004. Regulation of the European Parliament and of the Council of 29 April 2004 laying down specific hygiene rules for food of animal origin, 853/2004/CE. In: Official Journal, L 139/55, 30/04/2004.

European Commission, 2004. Regulation of the European Parliament and of the Council of 29 April 2004 laying down specific rules for the organization of official controls on products of animal origin intended for human consumption, 854/2004/CE. In Official Journal, L 155/206, 30/04/2004.

European Commission, 2004. Regulation of the European Parliament and of the Council of 29 April 2004 on official controls performed to ensure to varication of compliance with feed and food law, animal health and animal welfare rules 882/2004/CE. In Official Journal, L 165/1, 30/04/2004.

European Union Commission Implementing Regulation, 2015. Law 1375/2015 of 10 August 2015 laying down specific rules of official controls for Trichinella in meat 1375/2015/CE. In Official Journal, L212/7, 11/08/2015.

Gill CO, 2007. Microbiological conditions of meats from large game animals and birds. Meat Sci 77:149-60.

Italian Parliament, 1992. Norme per la protezione della fauna selvatica omeoterma e per il prelievo venatorio. Law n. 157 . 11/02/1992 In: Official Journal n. 46 25/02/1992.

Paulsen P, Smulders PJM, Hilbert F, 2012. Salmonella in meat from hunted game: a central Europe perspective. Food Res Int 45:609-16. 